\title{
Microwave spectroscopy of superfluid He II
}

\author{
K.A. Chishko and A.S. Rybalko \\ B. Verkin Institute for Low Temperature Physics and Engineering of the National Academy of Sciences of Ukraine \\ 47 Nauky Ave., Kharkiv 61103, Ukraine \\ E-mail: chishko@ilt.kharkov.ua
}

Received October 24, 2018

\begin{abstract}
Experimentally observed with dielectric disc resonator technique the resonant microwave absorptionamplification in superfluid He II below $\lambda$-point has been interpreted theoretically as a phenomenon in electrically active dielectric medium with low-energy excitations which exist near the ground state of the He-He interatomic bond due to fine structure of spin subsystem in condensed helium phase. The experimentally registered microwave resonant absorption line with $f_{\text {res }}=180.3 \mathrm{GHz}$ at $T=1.4 \mathrm{~K}$ and $f_{\text {res }}=150.0 \mathrm{GHz}$ at $T=2.1 \mathrm{~K}$ is closely related to the standard value of roton gap $\Delta / k_{B}=8.64 \mathrm{~K}(179.36 \mathrm{GHz})$. The measured temperature dependence of the resonant absorption demonstrates an excellent agreement with the corresponding neutron diffraction data for $\Delta(T)$ known from different literature sources. From the common point of view the obtained resonant absorption provides a typical example of the microwave spectroscopy which occurs widely among molecular systems with rotational and vibrational degrees of freedom, but for the first time discovered on as simple atomic matter as a superfluid helium. We explain the phenomenon as an effect of spin-phonon interaction within superfluid He II phase, and our theoretical estimation gives an upper limit $\sim 250 \mathrm{GHz}$ for the microwave resonant response of the system at $T=0$. We interpret the dielectric ${ }^{4} \mathrm{He}$ superfluid as an electrically active working substance for low temperature MASER, and clarify the atomic mechanism of microwave absorptionamplification in the condensed helium phases.
\end{abstract}

Keywords: superfluid He II, microwave absorption, He-He interatomic interaction, spin-phonon interaction.

\section{Introduction}

Microwave resonant absorption in He II was discovered experimentally with dielectric disc resonator (DDR) technique in a series of works [1-6]. However, for this moment the nature of the phenomenon is not quite understandable. The microwave adsorption in a dielectric medium implies that there exist low energy excitations (with energy of a few K) under the ground state of helium condensed phase. In a common sense the microwave absorption is some standard phenomenon in molecular systems [7] (including such a popular matter as simple water [8]) where external electromagnetic field activates rotational and vibrational modes with corresponding low-energy eigenstates. Condensed phases of helium possess neither vibrational nor rotational intra-atomic modes, so that we have to find the necessary objects among the really existing helium degrees of freedom (electrons, spins, phonons). Phonons seem to be an essential condition of the model, because the experimentally observed absorption is temperature-dependent [1-6], so that we need to propose a channel for transfer of energy from driving electromagnetic field to the heat of the condensed helium condensed matter. The resonant charac- ter of the absorption means that into the process have been involved some atomic degrees of freedom. The only processes with the corresponding energetic scale are spinpossessed relativistic interactions of order $1 / c^{2}$ (proportional to the fundamental ratio $\alpha^{2} / 4 \sim 4.2 \mathrm{~K}$, where $\alpha=1 / 137$ is Sommerfeld constant). We present experimental results related to detection of low energy excitation in superfluid He II with plausible theoretical interpretation of the phenomena.

\section{Experiment}

The experimental equipment is built of selective amplifier with dielectric disc resonator (DDR) mounted between two microwave antennas working both on in- and output of the microwave signal in the frequency range $120-250 \mathrm{GHz}$ $[1,2]$. The DDR is submerged into liquid ${ }^{4} \mathrm{He}$, so that the helium phase serves as 'intermediate connector' in the whole feedback loop circuit. Liquid helium is coupled with DDR through natural boundary conditions (both electrical and mechanical) at the external surface of the resonator, so that all the dielectric and hydrodynamic properties of the liquid helium directly manifest to integral response of the 
measuring system. The measurements are fulfilled in the temperature range $1.2-2.9 \mathrm{~K}$, i.e. both below and above $\lambda$ point. In the common sense the experiment is a measurement of permittivity dispersion in liquid dielectric ${ }^{4} \mathrm{He}$. The measuring cell is supplied with Kapitza 'thermal gun' [9] to produce hydrodynamic flow simulated by intrinsic heating elements with calibrated heat power [1].

Figure 1(a) illustrates the He II response for two temperatures, 1.4 and $2.1 \mathrm{~K}$. It characterized by transmission coefficient

$$
\delta=\delta_{b}+\left(A_{v}-A_{l}\right) / A_{v},
$$

where $A_{v}$ is amplitude of the signal in empty cell, $A_{l}$ is the response from helium-loaded cell, and $\delta_{b}$ is background contribution caused by intrinsic response of the measuring system. It is evident that $\delta>\delta_{b}$ (or $A_{v}>A_{l}$ ) means dielectric loss in the helium bath, but $\delta<\delta_{b}$ (and $A_{v}<A_{l}$ ) corresponds to amplification of the input signal. In the absence of heat flow within the measuring cell the system demonstrates a sharp resonant absorption peak whose position on the frequency axis is temperature-
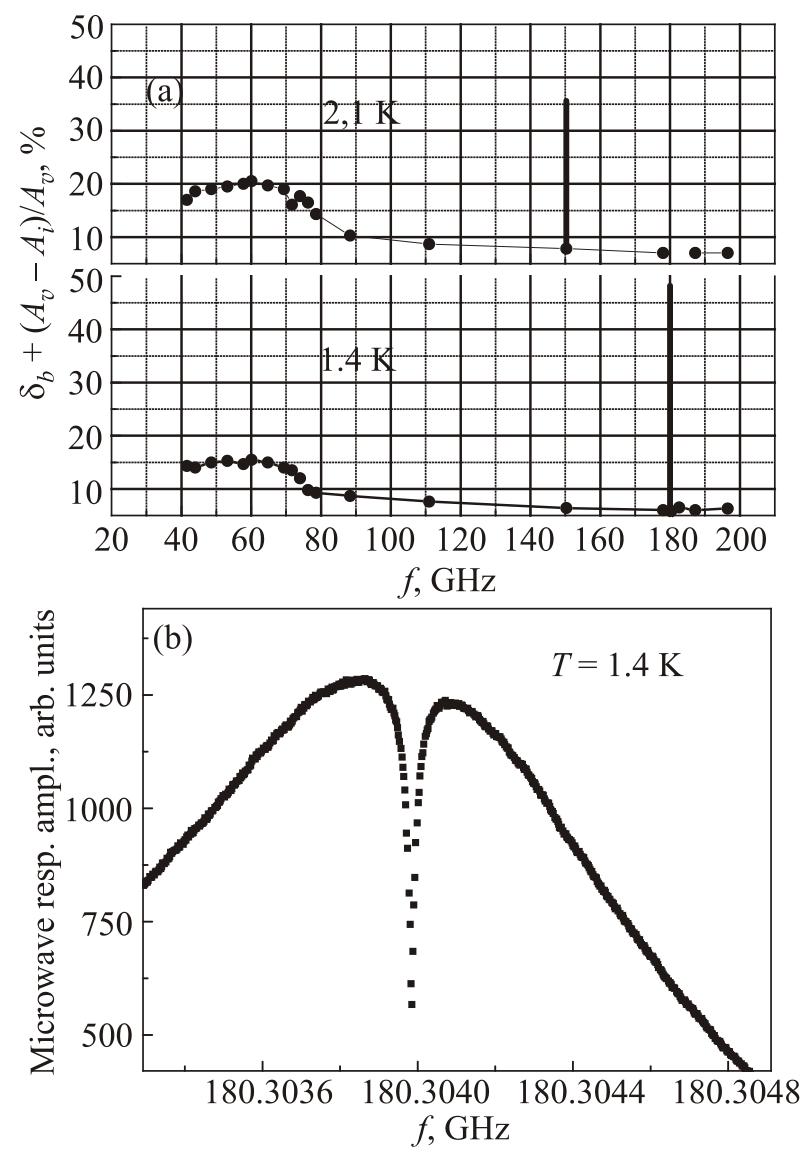

Fig. 1. Frequency dependence of the signal amplitude retrieved from the DDR within superfluid ${ }^{4} \mathrm{He}$ ( $A_{v}$ is amplitude in vacuum, and $A_{l}$ is the signal amplitude from the resonator coupled with surrounding liquid) at two temperatures below $\lambda$-point without thermal flow [1] (a). Response near the resonant absorption line at 180.3 GHz [1-4]. The frequency sampling is $2.5 \mathrm{kHz}$ [4] (b). dependent. Figure 1(b) shows the presence of the extremely narrow absorption line at $180.3 \mathrm{GHz}$ over the relatively 'wide' intrinsic resonant curve of the DDR. This experiment testifies to the fact that the absorption line has an atomic nature, but its manifestation depends principally on the physical state of the condensed phase where the atoms are connected through interatomic interactions. Thus, the interatomic interaction should be a principal point of investigation.

Figure 2(a) demonstrates the frequency positions of the absorption line as a function of temperature (black circles, see also Refs. 1, 4) in comparison with corresponding neutron diffractometry data extracted from two literature sources $[10,11]$. It can be seen a good agreement between the two dependences which is a direct evidence that the phenomenon of microwave absorption is an effect of atomic nature.

Figure 2(b) shows the same (as on Fig. 2(a)) temperature dependence of the absorption line position (black circles) relative to the averaged frequency response of the
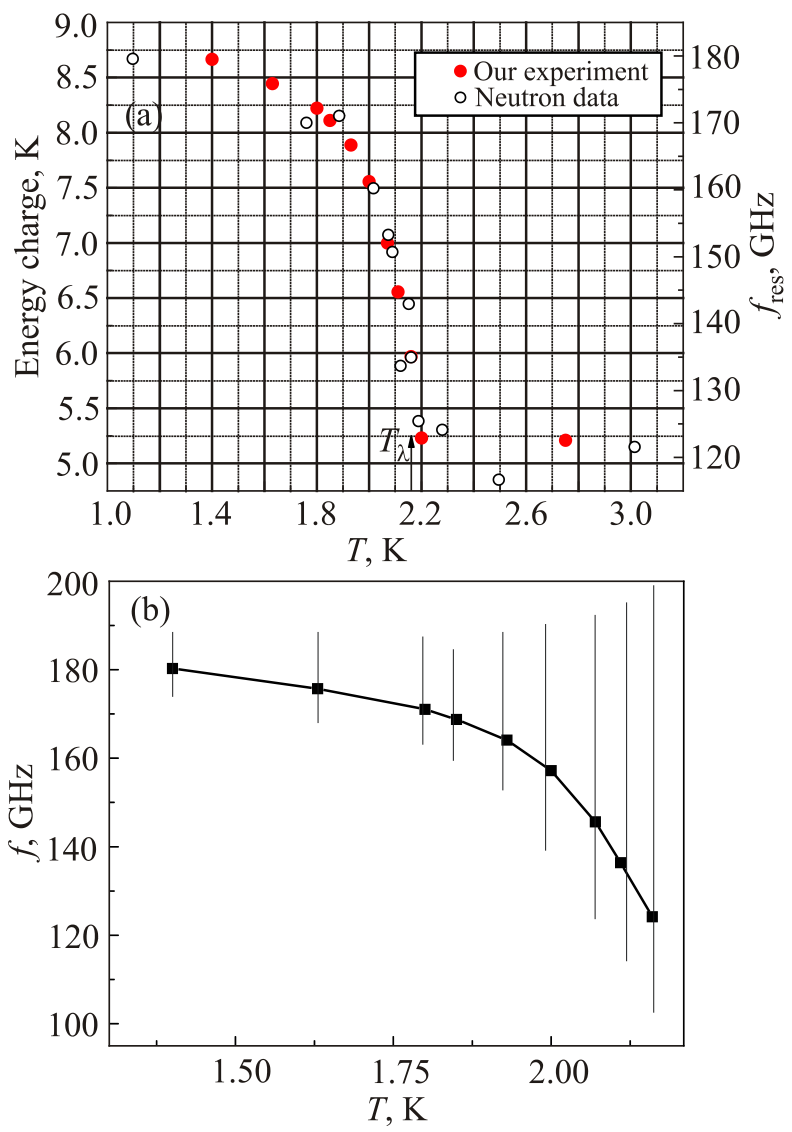

Fig. 2. (Color online) Temperature dependence of the absorption line position: comparison between our experiment and neutron data on roton gap [10,11] (see, also [12]) (a). Temperature dependence of the absorption line position relative to the averaged frequency response (amplitude envelope) of the loaded resonator (b). The length of each vertical line is proportional to the width of the effective resonant curve on the level $0.707(-3 \mathrm{~dB})$. The vertical line at the last left point (corresponding to absorption line of $180 \mathrm{GHz}$ ) is the same that the red horizontal mark on the plot Fig. 2. 
loaded resonator. At empty cell the resonator has a frequency response [4] which composed of narrow individual peaks with approximately constant amplitudes (tesseral surface harmonics or 'whispering gallery modes'). If the cell is filled with He II then the frequency response has been modified [4] in such a manner that the amplitude envelope of the flock of peaks attains a wide minimum encloses a number of the individual gallery modes. This modification is connected with a weak effect of electromagnetic boundary conditions in the contact between resonator and dielectric He II. The boundary coupling between DDR and surrounding helium leads to disturbance in He II medium due to ponderomotive forces and electromechanical effect from piezoelectric DDR. Such disturbance can produce only macroscopic hydrodynamic movements (sound waves) in the helium bath. The smooth but clearly observable peaks of the hydrodynamically conditioned absorption can be seen on Fig. 1(a), at frequencies 30-80 $\mathrm{GHz}$, which corresponds to sound wavelength of about 0.5 $\mathrm{cm}$ (and frequency of normal sound of $50 \mathrm{kHz}$ ). To produce the sound excitation we need spend some energy from the external electromagnetic pumping, and it is the channel of the normal electromagnetic absorption. The characteristic features of the normal absorption is the smooth frequency dependence of the absorption coefficient (the visible width of the $60 \mathrm{GHz}$ peak on the Fig. 1 is approximately $30 \mathrm{GHz}$ ).

Certainly, hydrodynamic loss exist also at higher frequencies. In Ref. 4 was shown that in the frequency range 165-200 GHz the initially flat frequency response of the empty cell with DDR changes radically in presence of liquid helium: i) the response amplitude decreases uniformly within the whole frequency range, and ii) the wide smooth 'cup' is formed with minimum (corresponding to maximum attenuation) at approximately $185 \mathrm{GHz}$ (see Fig. 1(a) and Fig. 1(b) from Ref. 4). But the most impressive thing is appearance of the narrow resonant absorption line over the smooth curve of the normal loses (see Fig. 3 in Ref. 4). In view of the strong resonant character of the phenomenon, it can not be associated with any hydrodynamic process. Indeed, the electromagnetic disturbance with wavelength near $1 \mathrm{~mm}$ should produce in hydrodynamic regime the first sound wave with frequency of $250 \mathrm{kHz}$, so that it is impossible to expect any sound-related specific response in $180 \mathrm{GHz}$ region. Thus, the absorption curve has the form of a wide 'pedestal' under sharp resonant peak (see Fig. 2 and Fig. 3 in Ref. 4. The pedestal can be characterized with 'width' on the level $0.707(-3 \mathrm{db})$ relative to maximun of the normal absorption (dash line in Fig. 2), and these widths mark in Fig. 2(b) any point corresponding to the absorption line with temperature-dependent position. Within the frequency scale in the Fig. 2(b) the plot of absorption line is only simple small point (black circles on Fig. 1(b)), its width is much lower than even the width of individual gallery harmonics (see Ref. 4). From the com- mon point of view the phenomenon under study is rather close to the anomalous dispersion in optics.

The main features of the phenomenon can be summarized as follows:

i) the position of the narrow absorption line corresponds exactly to the standard value [13,14] of the roton gap $\Delta / k_{B}=8.64 \mathrm{~K}(179.36 \mathrm{GHz})$;

ii) the microwave adsorption can be detected definitely only within superfluid phase below $\lambda$-point (above $\lambda$ point only weak response can be detected, the absorption curve 'spreads' as the temperature approaches $T_{\lambda}$, and at $T>T_{\lambda}$ the absorption becomes insufficient);

iii) the narrow adsorption line on the wide basic response curve of the individual microwave resonator mode means that the phenomenon is of atomic nature;

iv) when the temperature increases, the adsorption peak shifts to lower frequencies as it can be seen in Figs. 1(a) and 2(a), so that we observe a macroscopically cooperative effect caused by interatomic interactions and destroyed by density fluctuations within condensed helium phase, and this observed behavior is in good agreement with standard temperature dependence of the roton gap [14];

v) the observed low-temperature phenomenon can be interpreted only at presence of low-energy atomic excitations near the ground state of the helium atom.

The experiment presented in Fig. 3 was performed at pilot frequency $f_{\text {res }}=180.3 \mathrm{GHz}$ modulated from additional low-frequency pulse generator with controlled onoff time ratio of the output pulse sequence (the corresponding experimental setup has been described in Ref. 6). The voltage from the pulse generator powers the heaters of the flasks, so that they produced the narrow hydrodynamic jet (the nozzle cross-section of the gun flask is $1 \mu \mathrm{m} \times 1 \mathrm{~mm}$ [6]) slipping in the direct contact with the lateral surface of

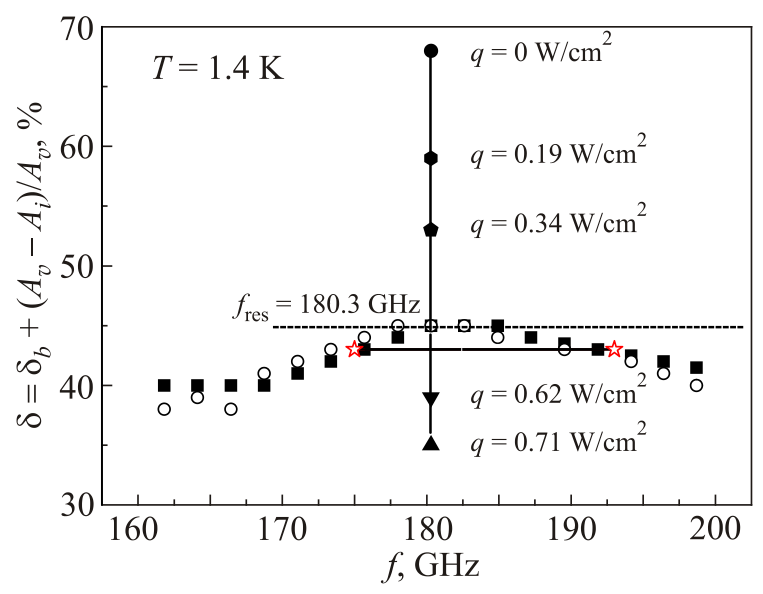

Fig. 3. (Color online) Microwave signal amplitude in atomic line $f_{\text {res }}=180.3 \mathrm{GHz}$ at different values $q$ of the heat flow from Kapitza thermal gun. The dash line marks the background (zero absorption) level at $f=f_{\text {res }}$. The black boxes and empty circles are intrinsic resonant curve the loaded of DDR, and the red horizontal line corresponds to the same mark on the plot in Fig. 2(b). 
DDR. This setup supports the permanent pulse-controlled absorption-irradiation process in the electrically active two-level ${ }^{4} \mathrm{He}$ medium which is the energy transporter within the completed circuit feedback loop on the subcircuit 'antenna-radiator' $\rightarrow$ helium $\rightarrow$ DDR $\rightarrow$ helium $\rightarrow$ 'antenna-transducer'. The integral energy transfer coefficient of the subcircuit is determined by the coherency in absorption-irradiation equilibrium which depends on the on-off time ratio of the heating pulse sequence and the transfer velocity of the liquid flow from the thermal gun. The absorbed portion of the heating energy is unable to be thermalized within the duration period between two subsequent pumping pulses due to extremely small number of thermal phonons at $T<T_{\lambda}$, so that 'heat' portion does not disperse in the liquid but will be absorbed on the lateral surface of DDR. The velocity of the hydrodynamic flow from thermal gun is approximately proportional to the thermal flow density $q$ from the flask, so that each experimental point on the characteristic line on Fig. 3 has been marked with the numerical value of the thermal flow in $\mathrm{W} / \mathrm{cm}^{2}$. The upper point corresponds to the flow-off situation $q=0$ and means the pure absorption of the pumping power. As the heat flow increases up to $q=0.19 \mathrm{~W} / \mathrm{cm}^{2}$ and $q=0.34 \mathrm{~W} / \mathrm{cm}^{2}$ the absorption becomes smaller and smaller, then at $q=0.19 \mathrm{~W} / \mathrm{cm}^{2}$ and $q=0.34 \mathrm{~W} / \mathrm{cm}^{2}$ we obtain progressive amplification of the signal (the negative feedback in the loop changes to positive one). And during the whole experiment at constant temperature $T=1.4 \mathrm{~K}$ the main response remains to be registered at $f_{\text {res }}=180.3 \mathrm{GHz}$ which means that we are dealing with intra-atomic transition between the ground state and a low-lying excited level.

\section{Discussion}

The microwave resonant adsorption has been detected definitely within superfluid phase below $\lambda$-point (above $\lambda$-point only weak non-resonant response can be detected, the absorption curve 'spreads' as the temperature approaches $T_{\lambda}$, and at $T>T_{\lambda}$ the absorption becomes insufficient), so that the effect has been destroying by fluctuation when approaching to the phase transition point. Thus, the resonant absorption phenomenon should be closely related to a certain structure ordering in the superfluid He II, but the nature of this order remains still unknown. Temperature dependence of the adsorption effect testifies that the energy of an external electromagnetic pumping transfers into medium heat through phonon degrees of freedom, so that we have to establish the mechanism of electromagnetic driving for mechanical degrees in continuous helium matter. In other words, we try to explain the electromechanical effect in superfluid He II. The external pumping are quasi-stationary electromagnetic fields because microwave frequencies are much lower as compared to characteristic Bohr frequencies for orbital motion of electrons (and wavelength of electromagnetic pumping is much higher than Bohr ra- dius). However, the sharp resonant character of the effect means that the absorption is based on some of microscopic (atomic) channels of energy transfer from the field to the condensed phase. The external electromagnetic field interacts with electronic and nuclear charges, electronic currents (orbital motion) and electronic spins (nuclear spin of ${ }^{4} \mathrm{He}$ atom is equal to zero). Thus, each of the mentioned channels can affect the phonon degrees of freedom, but we expect that spin-spin interaction on the interatomic bonds [15] seem to have the most suitable value to correspond the experimental observations.

The most essential result of the above-reported experiments on He II is the temperature-dependent narrow resonant absorption line discovered within microwave (with wavelength of 1-2 mm) frequency range 150-200 GHz. This result seems quite unexpected, because microwave activity with resonant response is known typical for gaseous, liquid and solid molecular systems [7] with lowenergy interatomic bonds, but had never been reported for the simple atomic media like liquid helium. In the case of liquid helium the effect can be realized if there exist a channel of resonant energy transfer from external electromagnetic field to phonon subsystem of the medium. In the common case the external electromagnetic irradiation can affect the thermodynamics of the macroscopic system through ponderomotive forces which lead to dielectric loss and hydrodynamic motions (first, second, third, etc. sounds) in the helium liquid. However, the resonant effect can appear only if external electromagnetic disturbance produces an intra-atomic transition with corresponding resonant frequency. Thus, to explain the nature of the resonant absorption in helium we have to find the mechanism of low-energy excitations in this system.

In the case of individual ${ }^{4} \mathrm{He}$ atom the only possible low-energy effect (of about $8 \mathrm{~K}$, or, more exactly, $167.9 \mathrm{GHz}$ [12], and this estimation is rather close to the standard value $8.64 \mathrm{~K}$ of the roton gap $[13,14]$ ) would be the transition between antisymmetric ( $\uparrow \downarrow)$ and symmetric ( $\uparrow$ ) spin states within a unitary helium shell. However, in view of strong antisymmetry of the complete (space plus spin) shell wave function the mentioned transition can not be realized spontaneously without simultaneous electron transition (between para and ortho helium), and this transition demands an enormous great energy (of order $19 \mathrm{eV}$ ) which can be obtained only from an external source. Thus, the necessary spontaneous low-energy transition can not be obtained from an individual helium atom, but the situation changes radically in helium condensed phases where all electrons (and their spins, respectively) are distributed between separated He-He bonds within a common macroscopic valence band which provides an existence of the stable helium condensed phase at the corresponding saturated vapor pressure. The ${ }^{4} \mathrm{He}-{ }^{4} \mathrm{He}$ bond consists of two nucleus connected by four electrons (and these electrons are involved simultaneously into others bonds with nearest 
neighboring atoms and, hence, they are collective electrons of the macroscopic valence band). In the paper [15] the ${ }^{4} \mathrm{He}-{ }^{4} \mathrm{He}$ bond $\left(\mathrm{He}_{2}\right.$ dimer) was studied as a rigorous solution of the corresponding Schrödinger equation within an exact diagonalization procedure. The results of [15] give more realistic picture based on the direct He-He interaction with relativistic corrections of order $1 / c^{2}$ (see Ref. 16). The spin density matrix, $\rho\left(\hat{\sigma}_{a}, \hat{\sigma}_{b}, \hat{\sigma}_{c}, \hat{\sigma}_{d} \mid R_{0}\right)$, for He-He bond is a formal analog of antiferromagnetic Heisenberg model applied to four-electron cluster within an integrated dimer [15],

$$
\rho\left(\hat{\sigma}_{a}, \hat{\sigma}_{b}, \hat{\sigma}_{c}, \hat{\sigma}_{d} \mid R_{0}\right)-E_{1}\left(R_{0}\right)=J\left(R_{0}\right) \sum_{s \neq s^{\prime}} \hat{\sigma} \hat{\sigma}_{s^{\prime}},
$$

where $\hat{\sigma}_{\alpha}\left(\alpha, s, s^{\prime}=a, b, c, d\right)$ are spin operators, $R_{0}$ is interatomic distance, and $J\left(R_{0}\right)=3.8 \cdot 10^{-5}$ arb. units = $=1.66 \cdot 10^{-15} \mathrm{erg}=12 \mathrm{~K}$ is exchange constant. In contrast with antisymmetric singlet of helium atomic shell the ground state of the four-spin cluster on $\mathrm{He}-\mathrm{He}$ bond is symmetric doublet (twice degenerated symmetric level) with energy $\mathcal{E}_{s}^{(0)} / J\left(R_{0}\right)=-6$ or $\mathcal{E}_{s}^{(0)} \cong-72 \mathrm{~K}$ (it is just twice higher than the spin energy of simple helium shell). In view of its symmetry this level can not serve as a ground state for ${ }^{4} \mathrm{He}_{2}$ dimer because its spatial ground state is naturally symmetric [15]. Thus, the spin ground state of the He-He bond is the next quintet of antisymmetric states with $\mathcal{E}_{s}^{(1)} / J\left(R_{0}\right)=-2$ or $\mathcal{E}_{s}^{(1)} \sim-24 \mathrm{~K}$ (see Ref. 15). Such the ground state on the He-He bond will be splitted even at $T=0$ due to zero-point motion of nucleus, and this splitting, $\Delta$, within a stable interatomic bond should be evidently lower then exchange, $\Delta<J\left(<R_{0}>\right) \sim 12 \mathrm{~K}=250 \mathrm{GHz}$ (this conclusion is supported by experimentally observed stability of both liquid and He II superfluid phases under their own saturated vapor pressures, and gives the upper limit for possible resonant effects in He II at external microwave electromagnetic disturbance). Dependence of exchange on the interatomic distances means coupling between spins and lattice phonons (the exchange $J\left(R_{0}\right)$ is an explicit function of the internuclear distance $R_{0}$ [15]). On the other hand, the splitting (of order a few Kelvins) should be temperature-dependent due to temperature dependence of $<R_{0}>$.

Within the lattice model of monoatomic phase with two spins ( $\hat{\boldsymbol{\sigma}}_{a}^{\mathbf{f}}$ and $\hat{\boldsymbol{\sigma}}_{b}^{\mathbf{f}}$ ) belong to each site with coordinate $\mathbf{f}$, we can write the Hamiltonian of the condensed phase as superposition of three terms, $\hat{H}=H_{\mathrm{ph}}+\hat{H}_{s s}+\hat{H}_{\mathrm{sph}}$. The first term, $H_{\mathrm{ph}}$, is the phonon Hamiltonian [16]. The second term describes the antiferromagnetic spin-spin interaction,

$$
\begin{gathered}
\hat{H}_{s s}=\frac{J\left(R_{0}\right)}{2} \sum_{\mathbf{f}, \mathbf{d}}\left[\hat{\boldsymbol{\sigma}}_{a}^{\mathbf{f}} \hat{\boldsymbol{\sigma}}_{a}^{\mathbf{f}+R_{0} \mathbf{d}+}\right. \\
+\hat{\boldsymbol{\sigma}}_{a}^{\mathbf{f}} \hat{\boldsymbol{\sigma}}_{b}^{\mathbf{f}+R_{0} \mathbf{d}}+\hat{\boldsymbol{\sigma}}_{b}^{\mathbf{f}} \hat{\boldsymbol{\sigma}}_{a}^{\mathbf{f}+R_{0} \mathbf{d}}+\hat{\boldsymbol{\sigma}}_{b}^{\mathbf{f}} \hat{\boldsymbol{\sigma}}_{b}^{\left.\mathbf{f}+R_{0} \mathbf{d}\right]}
\end{gathered}
$$

where $\mathbf{d}$ is a unit vector directed to the corresponding nearest neighbor from the first coordination sphere of the site $\mathbf{f}$. The lattice sites $\mathbf{f}$ and $\mathbf{f}+R_{0} \mathbf{d}$ have displacements $\mathbf{u}_{\mathbf{f}}$ and $\mathbf{u}_{\mathbf{f}, \mathbf{d}}$, respectively. And the last term,

$$
\begin{aligned}
& \hat{H}_{\mathrm{sph}}=\frac{\partial J\left(R_{0}\right)}{\partial R_{0}} \mathbf{f} \sum_{f, \mathbf{d}}\left[\mathbf{d}\left(\mathbf{u}_{\mathbf{f}, \mathbf{d}}-\mathbf{u}_{\mathbf{f}}\right)\right] \times \\
& \times\left[\hat{\boldsymbol{\sigma}}_{a}^{\mathbf{f}} \hat{\boldsymbol{\sigma}}_{a}^{\mathbf{f}}+\hat{\boldsymbol{\sigma}}_{a}^{\mathbf{f}} \hat{\boldsymbol{\sigma}}_{b}^{\mathbf{f}}+\hat{\boldsymbol{\sigma}}_{b}^{\mathbf{f}} \hat{\boldsymbol{\sigma}}_{a}^{\mathbf{f}, \mathbf{d}}+\hat{\boldsymbol{\sigma}}_{b}^{\mathbf{f}} \hat{\boldsymbol{\sigma}}_{b}^{\mathbf{f}, \mathbf{d}}\right],
\end{aligned}
$$

is the spin-phonon interaction (with $\partial J\left(R_{0}\right) / \partial R_{0}>0$ ) proportional to the both gradient of the lattice sites displacements and bilinear superpositions of the spin operators within a He-He bond [15]. It can be seen from Eq. (3) that spin subsystem plays the role of an external force for phonon excitations, and when approaching some 'resonant' wavelength the phonon dispersion curve will be 'subsided' due to loading from spin degrees of freedom (roton minimum of dispersion curve). Mechanically, it is rather evident effect which is just direct analog of translationrotation interaction in molecular cryocrystals [18-20] and could be a justification of the phonon-'roton' coupling in He II (phonons are translation excitations in the medium, but spin degrees of freedom have the well-known transformation properties of angular momentum). In this connection could be clarified the physical sense of term 'roton', introduced by I.E. Tamm in 1941 [21]. The phenomenon of microwave resonant absorption is manifestation of direct interaction between macro- and microscopic degrees of freedom in condensed helium phases, and concept of the spin-phonon interaction is quite realistic as the mechanism for a number of experimentally observed effects.

The temperature dependence of the frequency position of the characteristic lines (Fig. 1) is a direct consequence of interatomic interaction and spin-spin correlations in the neighboring atoms within condensed helium phase. In Ref. 15 the spectrum of $\mathrm{He}_{2}$ dimer has been studied and it was shown that the value of the low-energy level near the ground state is a function of $R_{0}$. As a result, the positions of characteristic lines in the condensed phase depends on the density of the phase and, hence, on external pressure, and, correspondingly, on the temperature. The thermal density fluctuations destroy the structure ordering in He II, and above $\lambda$-point the electrical activity of helium vanishes. On the present stage we can give only qualitative estimations of the experimentally observed phenomena, the rigorous interpretation of the experiment needs to build in future the rigorous solution of the problem on the behavior of the He-He bond under external electromagnetic field and effect of spin-phonon interaction on phonon thermodynamics of He II. Thus, the further experimental and theoretical investigations of the electrical activity of liquid and solid helium can clarify the mechanism of ordering at $\lambda$-transition in He II. 


\section{Conclusion}

We propose the physical mechanism of low energy excitations in condensed phases of ${ }^{4} \mathrm{He}$ based on the natural degrees of freedom belong to ${ }^{4} \mathrm{He}$ atom (spatial and spin variables of electrons and nuclei). This makes us possible to interpret the electrical activity of superfluid ${ }^{4} \mathrm{He}$ [1-6] and consider our setup as low-temperature retunable MASER with superfluid He II as working substance.

1. A. Rybalko, S. Rubets, E. Rudavskii, V. Tikhy, S. Tarapov, R. Golovashchenko, and V. Derkach, Phys. Rev. B 76, 140503 (2007).

2. A. Rybalko, S. Rubets, E. Rudavskii, V. Tikhy, V. Derkach, and S. Tarapov, J. Low Temp. Phys. 148, 527 (2007).

3. A.S. Rybalko, S.P. Rubets, E.Ya. Rudavskii, V.A. Tikhy, R.V. Golovashchenko, V.N. Derkach, and S.I. Tarapov, Fiz. Nizk. Temp. 34, 326 (2008) [Low Temp. Phys. 34, 254 (2008)].

4. A. Rybalko, S. Rubets, E. Rudavskii, V. Tikhiy, Y. Poluectov, R. Golovashchenko, V. Derkach, S. Tarapov, and O. Usatenko, Fiz. Nizk. Temp. 35, 1073 (2009) [Low Temp. Phys. 35, 837 (2009)].

5. A. Rybalko, S. Rubets, E. Rudavskii, V. Tikhiy, Y. Poluectov, R. Golovashchenko, V. Derkach, S. Tarapov, and O. Usatenko, J. Low Temp. Phys. 158, 244 (2010).

6. A.S. Rybalko, S.P. Rubets, E.Ya. Rudavskii, V.A. Tikhiy, R. Golovashchenko, V.N. Derkach, and S.I. Tarapov, arXiv: 0811.2114 [cond-mat.].

7. W. Gordy and R.L. Cook, Microwave Molecular Spectra, Wiley-Interscience, NY (1984).

8. A.N. Didenko, M.S. Dmitriev, and M.V. Lalayan, J. Commun. Techn. Electron. 57, 666 (2012).

9. P.L. Kapitza, Phys. Rev. 60, 354 (1941)

10. D.G. Henshaw and A.D.B. Woods, Phys. Rev. 121, 1266 (1961).

11. G. Zigmont, F. Mezei, and M.T.F. Telling, Physica B 388, 43 (2007).

12. R.V. Golovashchenko, O.V. Goroshko, A.V. Varavin, A.S. Plevako, and V.N. Derkach, Proc. 16th Int. Crimean Conf. Microwave and Telecommunication Technology, (CriMiCo’2006), Sevastopol (2006), p. 817.

13. R.J. Donnelly and P.H. Roberts, J. Low Temp. Phys. 27, 687 (1977).

14. R.J. Donnelly and C.F. Barenghi, J. Phys. Chem. Ref. Data 27, 1217 (1998).

15. K.A. Chishko, Fiz. Nizk. Temp. 44, 1394 (2018) [Low Temp. Phys. 44, 1097 (2018)].

16. H.A. Bethe and E.E. Salpeter, Quantum Mechanics of Oneand Two-Electron Atoms, Plenum, NY (1977)

17. K.A. Chishko, Fiz. Nizk. Temp. 44, 154 (2018) [Low Temp. Phys. 44, 114 (2018)].

18. T.N. Antsygina and V.A. Slyusarev, Teor. Math. Fiz. 77, 234 (1988).

19. T.N. Antsygina, M.I. Poltavskaya, and K.A. Chishko, Fiz. Tverd. Tela 44, 1215 (2002).
20. T.N. Antsygina, M.I. Poltavskaya, and K.A. Chishko, Fiz. Nizk. Temp. 29, 961 (2003) [Low Temp. Phys. 29, 720 (2003)].

21. L.D. Landau, J. Phys USSR 5, 71 (1941).

\section{НВЧ спектроскопія надплинного Не II}

\section{К.О. Чишко, О.С. Рибалко}

Резонансні поглинання-підсилення електромагнітної енергії НВЧ діапазону у надплинному Не II при температурах нижчих $\lambda$-точки, що спостерігаються за допомогою техніки діелектричного дискового резонатора, інтерпретовано теоретично як ефекти у електрично активному діелектричному середовищі, яке вміщує низькоенергетичні збудження, що існують поблизу основного стану міжатомного зв'язку Не-Не завдяки тонкій структурі спінової підсистеми у конденсованих фазах гелію. НВЧ лінії резонансного поглинання $f_{\text {res }}=180,3$ ГГц при $T=1,4$ К та $f_{\text {res }}=150$ ГГц при $T=2,1 \mathrm{~K}$, які експериментально спостерігаються, однозначно корельовані зі стандартним значенням величини ротонної щілини $\Delta / k_{B}=8,64 \mathrm{~K}$ (179,36 ГГц). Виміряна температурна залежність резонансного поглинання добре узгоджується з різними літературними даними по $\Delta(T)$. Згідно $з$ загальноприйнятими уявленнями резонансне поглинання, яке спостерігається у НВЧ діапазоні, $є$ ефектом, типовим для молекулярних систем з обертальними та коливальними ступінями свободи, однак про це явище вперше повідомлюється для такого простого атомарного середовища як надплинний гелій. Ми пояснюємо це явище як ефект спін-фононної взаємодії у надплинній фазі Не II. Наша теоретична оцінка дає верхню границю $\sim 250$ ГГц щодо НВЧ резонансного відгуку системи при $T=0$. Ми інтерпретуємо надплинний діелектрик ${ }^{4} \mathrm{He}$ як електрично активне робоче середовище для низькотемпературного MASERa та пояснюємо атомарний механізм НВЧ поглинання-підсилення у конденсованих фазах гелію.

Ключові слова: надплинний Не II, НВЧ поглинання, міжатомна взаємодія Не-Не, спін-фононна взаємодія.

\section{СВЧ спектроскопия сверхтекучего Не II}

\section{К.А. Чишко, А.С. Рыбалко}

Резонансные поглощения-усиления электромагнитной энергии СВЧ диапазона в сверхтекучем Не II при температурах ниже $\lambda$-точки, наблюдаемые с помощью техники диэлектрического дискового резонатора, интерпретированы теоретически как эффекты в электрически активной диэлектрической среде, содержащей низкоэнергетические возбуждения, существующие вблизи основного состояния межатомной связи Не-Не благодаря тонкой структуре спиновой подсистемы в конденсированных фазах гелия. Экспериментально регистрируемые СВЧ линии резонансного поглощения $f_{\mathrm{res}}=180,3$ ГГц 
при $T=1,4$ К и $f_{\text {res }}=150$ ГГц при $T=2,1$ К однозначно коррелированны со стандартным значением величины ротонной щели $\Delta / k_{B}=8,64$ К (179,36 ГГц). Измеренная температурная зависимость резонансного поглощения демонстрирует прекрасное согласие с литературными данными по $\Delta(T)$. Согласно общепринятым представлениям, наблюдаемое резонансное поглощение в диапазоне СВЧ является эффектом, типичным для молекулярных систем с вращательными и колебательными степенями свободы, однако об этом явлении впервые сообщается для простой атомарной среды - сверхтекучего гелия. Мы объясняем это явление как эффект спин-фононного взаимодействия в сверхтекучей фазе Не II. Наша теоретическая оценка дает верхнюю границу $~ 250$ ГГц для СВЧ резонансного отклика системы при $T=0$. Мы интерпретируем сверхтекучий диэлектрик ${ }^{4} \mathrm{He}$ как электрически активную рабочую среду для низкотемпературного MASERa и объясняем атомарный механизм СВЧ поглощения-усиления в конденсированных фазах гелия.

Ключевые слова: сверхтекучий Не II, СВЧ поглощение, межатомное взаимодействие Не-Не, спин-фононное взаимодействие. 